\title{
Assessment of the learning curve of video-assisted thoracoscopic sympathectomy in a single neurosurgical trainee: a cumulative summation analysis
}

\author{
Hazem M. Alkosha ${ }^{1 *}$ (1) and Yasser M. Elkiran ${ }^{2}$
}

\begin{abstract}
Background: Video-assisted thoracoscopic sympathectomy (VATS) is a common procedure unusually practiced by neurosurgeons due to lack of training.

Objective: To evaluate the learning curve for VATS in a young neurosurgeon with no previous experience in open sympathectomy techniques or extracranial endoscopic procedures.

Methods: This is a retrospective review and analysis of prospectively collected data in 50 consecutive cases admitted to our facility with the diagnosis of essential palmar and axillary hyperhidrosis operated by a neurosurgical trainee under strict supervision of 2 experienced mentors. After an initial training phase, cumulative sum mation (CUSUM) analysis was used to evaluate the surgical performance of the trainee in terms of operating time, blood loss, hospital stay and failures.

Results: Improvement in operating time was noticed after the first 20 cases with significant affection by changes in OR team. The blood loss was significantly improved after the first 10 cases with less sensitivity to changes in OR team. Hospital stay and failures were steady and within expected values throughout the study.

Conclusion: An average of 20 cases may be enough for a neurosurgeon with basal knowledge to attain technical competence in VATS sympathectomy. Mentored surgical training on VATS sympathectomy is a safe and effective training method with failures within expected limits. The experience of the OR team plays an important role in the rapid improvement and consistency of performance.
\end{abstract}

Keywords: Learning curve, Sympathectomy, Cumulative sum, Thoracoscopy

\section{Introduction}

Since its first performance in 1889 [1], surgical sympathectomy has been evolving over years. Several early uses of sympathectomy [1-9] were discarded, rendering others as current indications [10-15], primarily palmar hyperhidrosis. Parallel to this, an evolution in techniques

\footnotetext{
*Correspondence: hazem.kosha@gmail.com; hazem_kosha@yahoo.com ${ }^{1}$ Department of Neurosurgery, Mansoura University Hospital, Gomhurria Street, Mansoura, Egypt

Full list of author information is available at the end of the article
}

started by perivascular sympathectomy $[16,17]$ and nervous fascicular dissociation [18], followed by ganglionectomy [19], diathermy ablation [20], radiofrequency [21] and clipping [22]. Thoracic sympathectomy was initially approached by classic posterior [23, 24], supraclavicular [25], anterior transthoracic [20, 26] and transaxillary approaches [27]. However, minimally invasive sympathectomy introduced by Hughes [28] then Kux [29] supplanted all these techniques and became the standard technique for upper thoracic sympathectomy [30]. 
Despite being commonly performed by thoracic and vascular surgeons; video-assisted thoracoscopic sympathectomy (VATS) is rarely practiced by neurosurgeons who favor open sympathectomy or case referral because of anatomical unfamiliarity and lack of training. The aim of this study was to evaluate the learning curve for VATS in a young neurosurgeon with no previous experience in open sympathectomy techniques or extracranial endoscopic procedures.

\section{Methods}

\section{Study design}

Cumulative summation (CUSUM) analysis of a case series of video-assissted thoracoscopic sympathectomy (VATS) for essential hyperhidrosis operated by a neurosurgical trainee mentored by the authors.

\section{Mentors and trainee}

The authors mentored a neurosurgical resident with no experience in sympathectomy or extracranial endoscopic procedures to evaluate the learning curve of VATS in trainees with basal knowledge. An initial 2-staged "training phase" was conducted. During the first stage, the trainee read 10 most-relevant articles and watched 20 demonstrated video clips of VATS performed by mentors. In the second stage the trainee got evaluated as an assistant using a $(0-10)$ scale in several VATS procedures. The evaluation score was the mean score by both mentors or the evaluation score of the only attending mentor. When the trainee achieved an acceptable level of orientation, he started a "practice phase" in which he performed 100 VATS procedures, bilaterally in 50 consecutive cases with essential hyperhidrosis under strict supervision of the mentors. During the procedures, no intervention was performed by mentors except in near misses or when the trainee faced a technical challenge or a complication. A note or advice given by the mentor was considered a minor intervention, while manual control or taking over by the mentor was a major intervention.

\section{Patients}

Between August 2015 and October 2018 following approval of local IRB, 50 consecutive cases with essential palmar and axillary hyperhidrosis were included after giving informed written contents and excluding secondary hyperhidrosis. All demographic, clinical and operative data was collected prospectively. Hyperhidrosis was severe (score 3 or 4) according to Hyperhidrosis Disease Severity Scale (HDSS) [31]. All patients tried unsuccessful non-operative management for variable durations. Patients were 15 years or older to suit the telescope size and ports in the endoscopic setup.

\section{Operative and postoperative methods}

Patients were operated under general anesthesia using HOPKINS $^{\circledR}$ II forward -oblique telescope $30^{\circ}$, provided by KARL STORZ ${ }^{\circledR}$ SE \&Co. KG, Tuttlingen, Germany. The surgical details of thoracic sympathectomy was described by the authors elsewhere [13]. Electrocautary ablation of the third and the fourth thoracic sympathetic ganglia were performed for palmar and axillary hyperhidrosis. Blood loss was estimated in mls; including blood collected in suction device and that in used surgical gauzes. Blood volume in soaked gauzes was calculated as the difference in weight between pre-used gauzes and those immediately discarded from the surgical field; then substituting $1 \mathrm{ml}$ for every $1 \mathrm{~g}$ increase in weight [32]. Weight measurements were performed using Digi DS-673SS Waterproof Swab Scale with 1 g graduations. The duration of surgery was defined as the time passed between the first skin incision and last skin suture using a digital stopwatch controlled by the anesthetist. Following surgery, patients were transferred to the recovery room for at least $1 \mathrm{~h}$ for monitoring of vital signs and ensuring equal air entry until full recovery. Oral fluids were allowed once patients became alert. After $3 \mathrm{~h}$, a plain chest X-ray was performed. Postoperative pain was controlled without narcotic analgesics using IV paracetamol or/and IM NSAIDs. At $6 \mathrm{~h}$, postoperative pain was estimated using a 0-10 Numeric Pain Intensity Scale (NPIS) in all patients. Patients were discharged on the same day of surgery unless they were hemodynamically unstable, having $\mathrm{SO}_{2}<95 \%$, showing abnormality on chest X-ray or pain scores of 5 or more. These abnormalities indicated longer hospitalization for stabilization.

\section{Outcome measures}

Early outcome ( 2 weeks after surgery) was evaluated by the improvement rate in sweating. Improvement rate was estimated as: (Preoperative HDSS - postoperative HDSS/preoperative HDSS $\times 100$. Short-term outcome (at 3 months) was evaluated using Hyperhidrosis Quality-of-Life Questionnaire (HQLQ) [33]. Complications were either; technique- or procedure-related. Techniquerelated complications as: intercostal neuralgia, Horner's syndrome, injury to an intrathoracic structure, incisionrelated complications, hemo- or/and pneumothorax and surgical emphysema were considered, while procedurerelated complications like bradycardia, excessive hand dryness and compensatory sweating were excluded; being undesirable effects of sympathectomy rather than related to the learning curve. Technique-related complications were classified as minor or major complications according to Clavien and his colleagues [34]. Failures included: "technical failures" like major intervention by the mentor, 
conversion to open thoracotomy and technique-related major complication; and/or "outcome failures" like improvement rates $\leq 50 \%$ in early outcome assessment and/or HQLQ scores more than 51 at 3-month.

\section{Statistical analysis}

The learning curve was quantitatively assessed using cumulative summation (CUSUM) analysis of the following parameters: operating time (OT), estimated blood loss (EBL), length of hospital stay and failure. The CUSUM charts for continuous data were introduced by Page [35] to address small shifts of the tested parameter and to monitor its deviation from a target value. Analysis of the binary outcome (success vs. failure) was presented by cumulative log-likelihood ratio chart, adapted from Rogers and colleagues [36].

After testing normality by Shapiro-Wilk test, continuous data was described in mean $\pm \mathrm{SD}$ or in median and IQR. Categorical data was described as numbers and percentages. Continuous data was compared using unpaired Student $t$ test when normally distributed or using Kruskal-Wallis and Mann-Whitney tests when not normally distributed, while categorical data was compared using Chi-Square test. Data was analyzed using IBM SPSS Statistics for Windows, Version 20.0. Armonk, NY: IBM Corp., 2011 and curves were created by Microsoft Excel 2010 with QI Marcos add-in.

\section{Results}

The timeline of study and evaluation scores of the trainee are presented (Figs. 1 and 2, respectively). The demographic data of patients are presented in Table 1 . The operating time ranged from 11 to $42 \mathrm{~min} /$ procedure (median of 16 and IQR of $7 \mathrm{~min}$ ). Initially, the CUSUM curve showed sharp upward drift exceeding the upper CUSUM line (out-of-control process) followed by a noticeable downward trend to reach below the upper CUSUM line by the 15 th procedure. However, at the 39 th procedure (20th case) the curve showed again a sharp

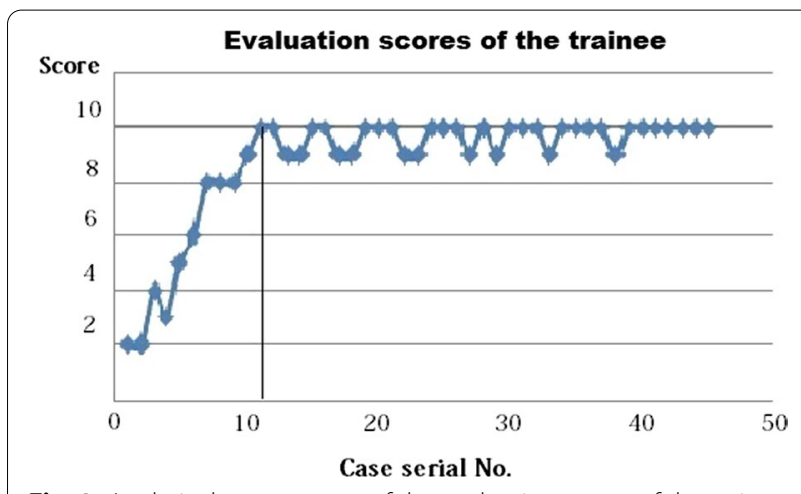

Fig. 2 A relatively steep curve of the evaluation scores of the trainee during training phase with a plateau at the 10 th case, revealing a rapid acquisition of anatomical and setup orientation. The score ranged between 2 and 10 with an overall mean of 8.8

upward trend to reach above the upper CUSUM line. This was coincidental with the shift of procedures from vascular to neurosurgical operating theater because of technical challenges. By the 44th procedure, the curve crossed again the upper CUSUM line downward to reach a steady state and remained fluctuating randomly around the zero line till the end of the study (Fig. 3).

The EBL ranged from 10 to $74 \mathrm{ml} /$ procedure (median of 14 and IQR of $10 \mathrm{ml}$ ). Initially, the curve drifted sharply above upper CUSUM line, then showed a downward trend to cross the control line at the 23rd procedure and flattens by the 27th. Similarly, the curve again deflected upward at the 39th procedure when the OR team was replaced, but unlike in CUSUM of operating time; the curve of EBL remained under the upper CUSUM till its downward slope again by the 42 nd procedure to reach a steady state till end of analysis (Fig. 4).

Patients spent $0-3$ nights inside the hospital following surgeries (Table 2). The CUSUM curve showed expected hospital stay during first 12 cases where the curve, although not steady, was running between upper and lower limits. In the cases 14 and 15 the curve spiked

\section{The whole length of study $=44$ months}

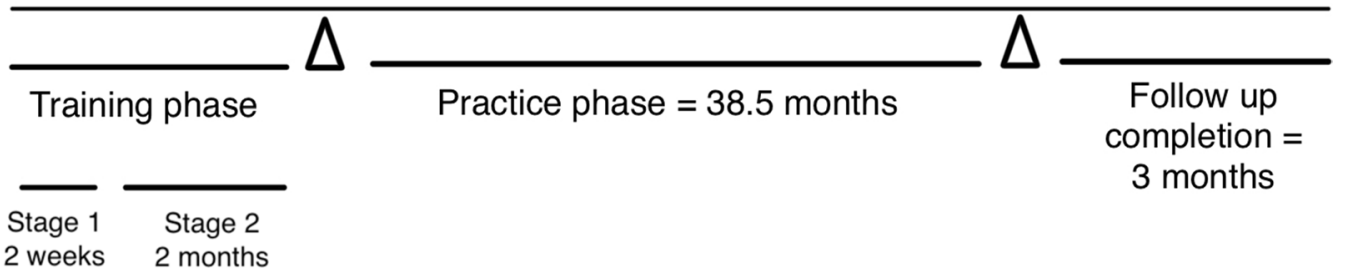

Fig. 1 The timeline of the whole study including; a 2 weeks of academic orientation about the indications, technique, complications and outcome of VATS via literature review and watching illustrated relevant videos for VATS, b 2 months of surgical assistance for anatomical and setup orientation, c 38.5 months of practicing 100 VATS procedures under strict supervision and $\mathbf{d} 3$ months for follow completion of last operated cases 
Table 1 Demographic data of patients in the study

\begin{tabular}{lcccrc}
\hline & Total & Females & Males & $\boldsymbol{p}$ value & Statistical test \\
\hline Number (\%) & $50(100 \%)$ & $32(64 \%)$ & $18(36 \%)$ & & \\
Mean age & $18.9(2.7)$ & $18.1(2.5)$ & $20.3(2.5)$ & 0.005 & Independent samples $T$ test \\
Mean BMI (SD) & $25(2.6)$ & $26.1(1.9)$ & $23.1(2.5)$ & $<0.001$ & Independent samples $T$ test \\
\hline
\end{tabular}

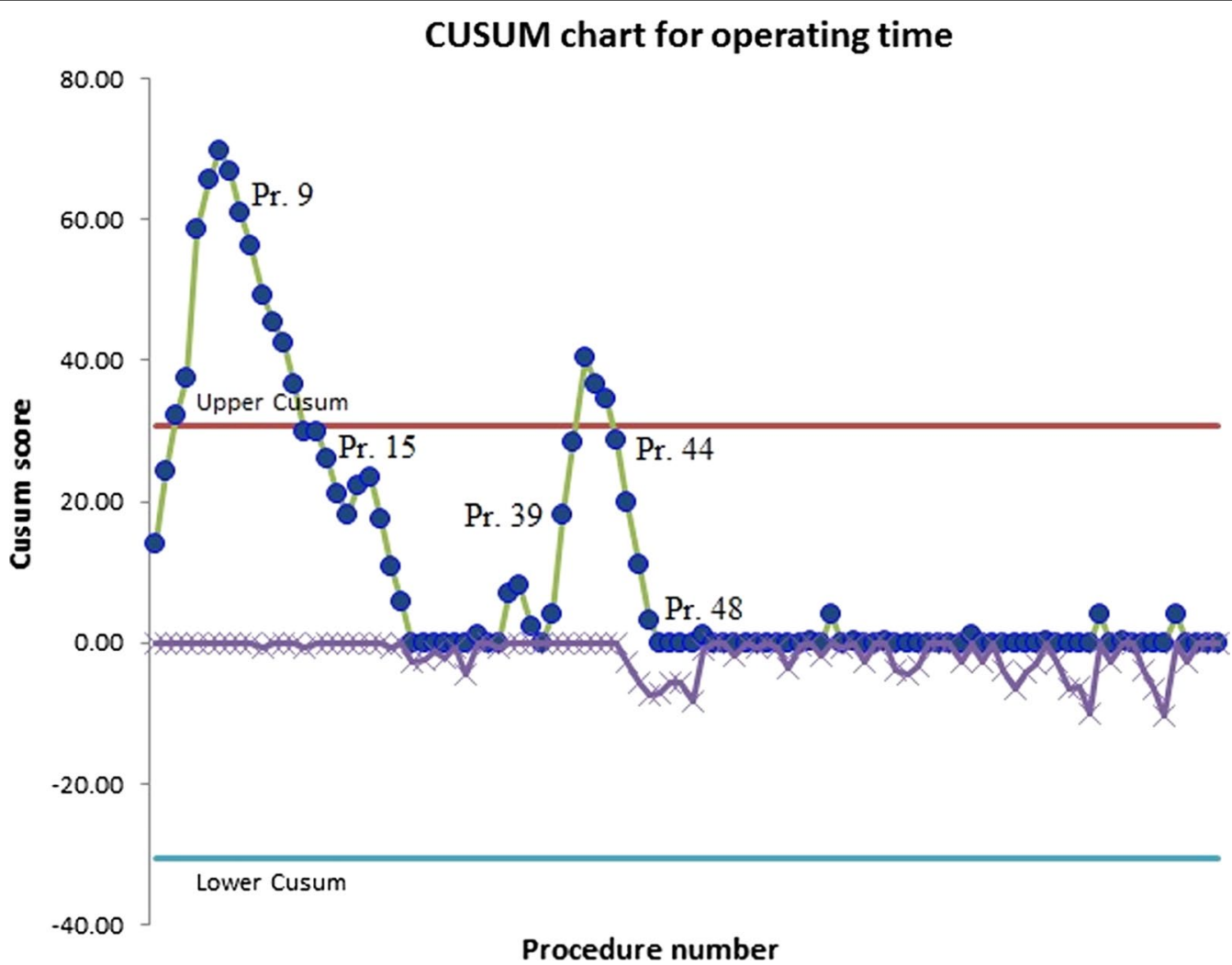

Fig. 3 CUSUM analysis of operating time revealed beginning of improvement at the 9th procedure, controlling the duration at the 27th procedure and reaching steady state at the 53rd procedure. Between the 39th and 42nd procedures there was an upward deflection of the curve above the upper CUSUM line (out-of-control process) due to OR team replacement

above the upper limit indicating that the cumulative nights of stay was out-of-control. However, from case 16 progressive improvement was noted and the process became under control till a flat curve was reached at the 20th case (Fig. 5). Four cases (8\%) were reported as failures in this study (Table 3). Persistent intercostal neuralgia was reported as a cause of failure in two cases and were managed in pain clinic by periodic intercostal nerve blocks. The CUSUM graph for failure fluctuated randomly around central line within the upper and lower CUSUM limits indicating within expected performance (Fig. 6).

The procedures were split into 5 groups; 20 successive procedures each. The groups were compared regarding operative time, EBL, hospital stay and outcome. The operative time dropped significantly after the second group $(p=0.003)$, indicating a significant improvement in operative time following the first 40 procedures (20 cases). On the other hand, the EBL showed a reduction after the first 20 procedures $(p=0.002)$. In contrary, the hospital stay and outcome showed no significant difference between groups (Kruskal-Wallis, $p=0.235$ and Pearson Chi-square, $p=0.695$, respectively).

\section{Discussion}

The CUSUM technique is a sequential analysis that permits an observer to decide whether the performance variation within or beyond the expected random variation to 


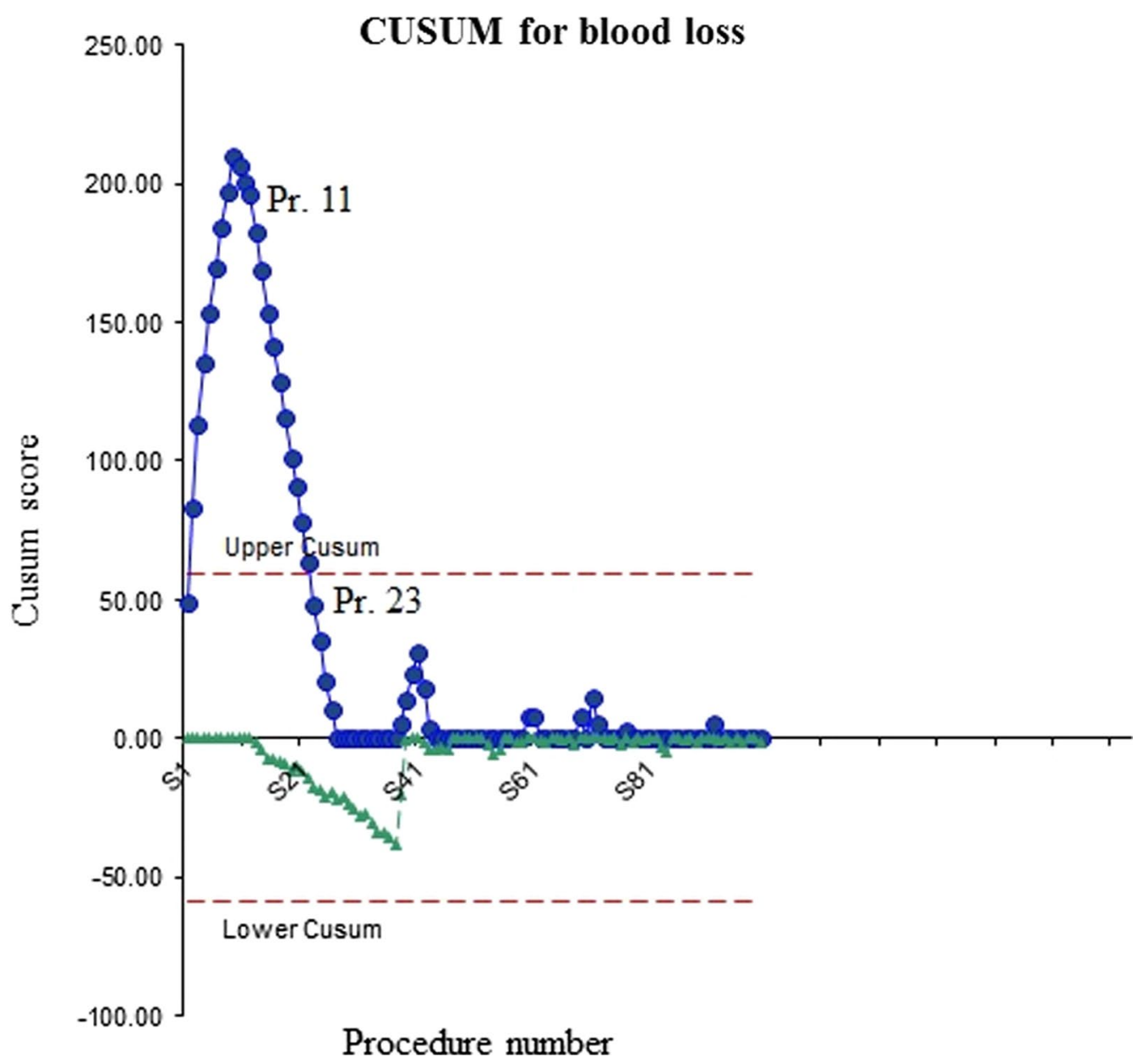

Fig. 4 CUSUM analysis of estimated blood loss (EBL); shows improvement of hemostasis by the 13th procedure, full control by the 29th procedure and proficiency at the 45 th procedure

Table 2 Length of hospital stay and postoperative conditions

\begin{tabular}{|c|c|c|c|c|}
\hline Number of cases & Length of stay & Postoperative status & Chest radiography & Management \\
\hline 1 case & 3 nights & $\begin{array}{l}\text { Unilateral moderate }(6 / 10) \text { chest pain } \\
\text { Mild dyspnea on exertion with } \mathrm{SO}_{2} 94 \% \\
\text { Hemodynamically stable }\end{array}$ & $\begin{array}{l}\text { Minor pneumothorax } \\
\text { ipsilateral to the side } \\
\text { of pain }\end{array}$ & $\begin{array}{l}\text { Conservative management using IV } \\
\text { paracetamol + IM NSAIDs }+\mathrm{O}_{2} \text { sup- } \\
\text { ply. Resolution at } 36 \mathrm{~h}\end{array}$ \\
\hline 1 case & 2 nights & $\begin{array}{l}\text { Bilateral chest pain }(5 / 10) \\
\text { Mild dyspnea on exertion with } \mathrm{SO}_{2} 96 \% \\
\text { Hemodynamically stable }\end{array}$ & Negative & $\begin{array}{l}\text { Conservative management using IV } \\
\text { paracetamol + IM NSAIDs + respira- } \\
\text { tory exercises }\end{array}$ \\
\hline 1 case & 2 nights & $\begin{array}{l}\text { Unilateral chest pain }(5 / 10) \\
\text { No dyspnea } \\
\text { Hemodynamically stable }\end{array}$ & Negative & $\begin{array}{l}\text { Conservative management using IM } \\
\text { NSAIDs }\end{array}$ \\
\hline 9 cases & 1 night & $\begin{array}{l}\text { Unilateral/bilateral chest pain (5 and 6/10) } \\
\text { No dyspnea } \\
\text { Hemodynamically stable }\end{array}$ & Negative & $\begin{array}{l}\text { Conservative management using IM } \\
\text { NSAIDs }\end{array}$ \\
\hline 38 cases & $<1$ night & $\begin{array}{l}\text { Negligible chest pain }(2-4 / 10) \\
\text { No dyspnea } \\
\text { Hemodynamically stable }\end{array}$ & Negative & $1 \mathrm{gm}$ of IV paracetamol \\
\hline
\end{tabular}




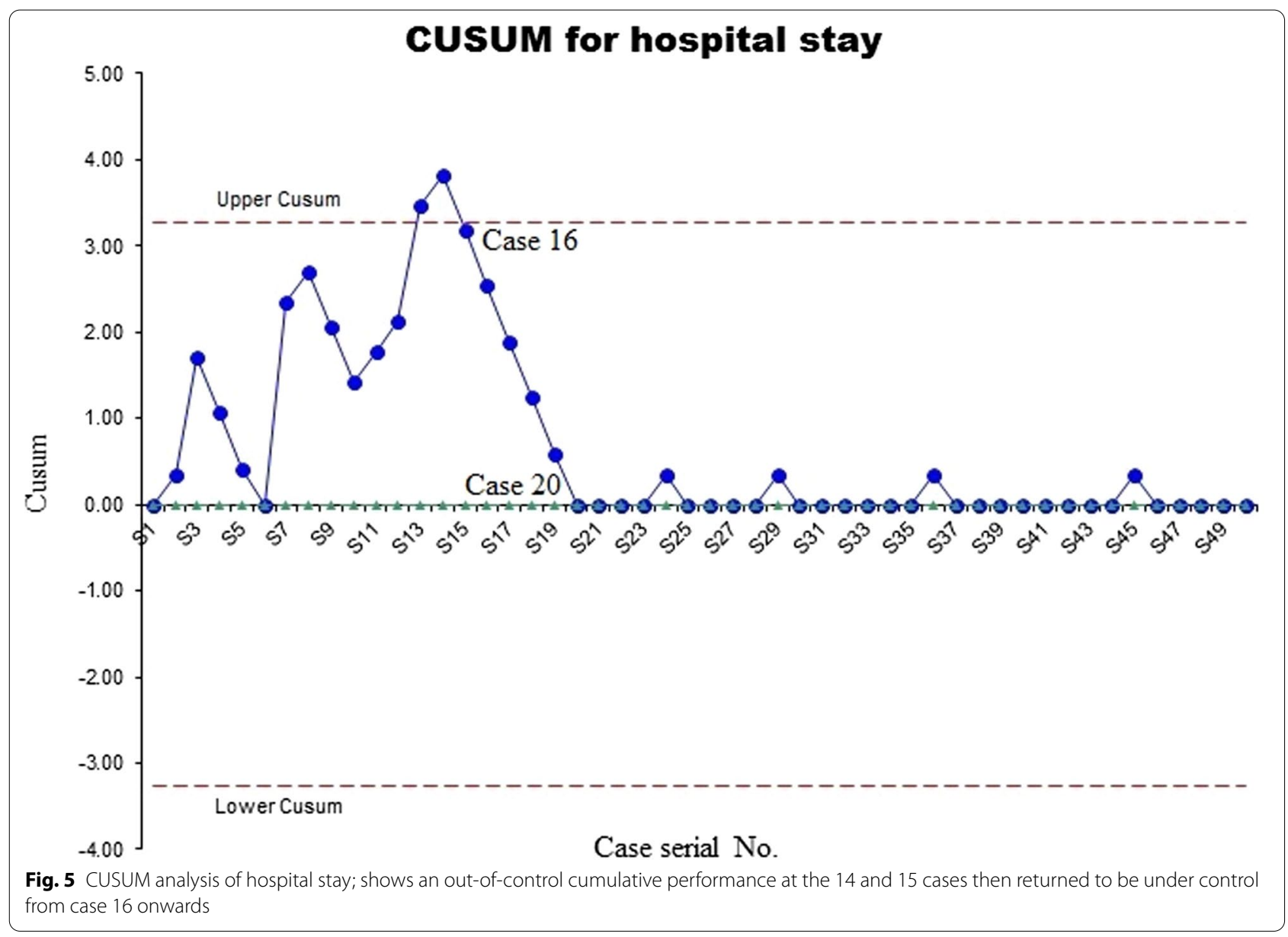

Table 3 Procedures with reported failures during the study

\begin{tabular}{ll}
\hline Procedure no & Type of failure \\
\hline Case 5 & Major intervention by the mentor (both sides; due to adhesions) \\
& Persistent intercostal neuralgia (left side) \\
& Improved HDSS: $33.3 \%$ \\
& HQLQ $=74$ \\
Case 8 & Major intervention by mentor (right side; near miss) \\
& Persistent intercostal neuralgia (left side) \\
& Improved HDSS: $33.3 \%$ \\
Case 19 & HQLQ $=77$ \\
& Major intervention by mentor (left side; confusing anatomy) \\
Case 32 & Improved HDSS: $50 \%$ \\
& Improved HDSS: $25 \%$ \\
& HQLQ $=55$
\end{tabular}

evaluate the competence of trainees [36-39]. Such technique proved useful in demonstrating the learning curve associating new-skill acquisition in an objective manner and documentation of competence in practice among trainees. We conducted the CUSUM analysis using sequential probability ratio testing which was found to provide a more sensitive analysis of the performance in progress, when there is rapid enhancement in the skills 


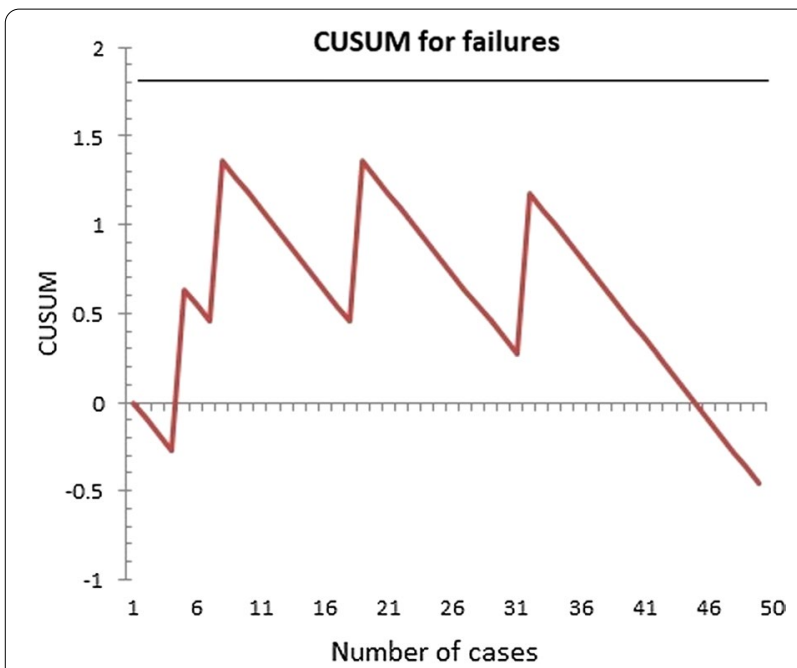

Fig. 6 CUSUM curve for failures; reveals within expected outcomes. The curve remains between the upper and lower CUSUM limits all through the study

level (training situation), compared to cumulative failure charting [40]. The trainee showed a steep curve of evaluation scores indicating rapid acquisition of orientation reaching a plateau at the 10th case that remained steady during the "training phase".

The CUSUM chart for the operating time showed an initial out-of-control process coinciding with consolidating anatomical orientation, acquiring manipulation skills and getting integrated into the OR team. By the 5th case, gradual improvement was noticed as the trainee acquired more confidence, hand dexterity, and more integration into the OR team. By the 8th case, the process became under control and toward a steady state till the OR shift happened at the 20th case. In the neurosurgical OR, a new team was integrated and the operating time became significantly longer. This deviation continued over 6 procedures, after which the curve regained its downward slope till the state of competency was achieved when the curve flattened at the 24th case. It was noticed that although the experience of both the surgeon and the OR team can impact the operation time; the impact of the surgeon's experience was more obvious on the CUSUM curve. It took about 7 cases for the practicing surgeon to keep the operating time under control in the presence of an experienced OR team, while control was fulfilled over just 3 cases when the practicing surgeon who got some experience operated with an inexperienced team.

Although it took more time by the trainee before blood loss became under control compared to operating time, the acquired skill of hemostasis was less affected by the OR team replacement than did the operating time. This was revealed by a curve that remained under the upper
CUSUM line indicating an under-control process. Moreover, the trainee reached competency in hemostasis earlier than he did regarding the operating time.

The CUSUM chart of failure showed inconclusive evidence about performance in which no trend was noticed and failures were as expected. This means that the procedure is generally feasible and undemanding for trainees. There was no procedure that turned open during the study. Moreover, no catastrophic complications were encountered resulting in death or major deficits. The success rate in this series reached $92 \%$ of cases which is comparable to other studies $[41,42]$. However, this may carry some optimism, as long-term outcomes like recurrence were not included. The major interventions by mentors were considered potential failures as major complications were expected in case these procedures were accomplished by the trainee. Improvements of $50 \%$ or less in HDSS (8\% of cases) and HQLQ scores more than 51 at 3 months (6\% of cases) were also considered failures. The two cases of intercostal neuralgia ( $4 \%$ of cases) were managed successfully by the pain control team; however, they were included among failures as they were considered disabling complications requiring repeated intercostal blocks. Although a significant improvement in blood loss was noted after the first 10 cases and a similar improvement in operative time after the first 20 cases, failures and hospital stays showed no significant differences among groups. This indicates that the procedure is generally safe and effective with a steep learning curve and rapid acquisition of skills over time even in young neurosurgeons with no experience in open sympathectomy or extracranial endoscopy.

\section{Conclusion}

Mentored surgical training on VATS sympathectomy proved to be a safe and an effective training method with detected failures within expected limits. We found it reasonable to consider an average of 20 cases to be a prerequisite for a neurosurgeon with basal knowledge to attain technical competence in VATS sympathectomy. The experience of the OR team plays an important role in the rapid improvement and consistency of performance. These results should be reproduced by analyzing the performance of more neurosurgical trainees to adjust for personal variations.

\section{Acknowledgements \\ Not applicable.}

\section{Authors' contributions}

Both authors mentored the trainee although the study. HA analyzed and interpreted the trainee's performance and was a major contributor in writing the manuscript. YE shared in data analysis and outcome assessment. Both authors read and approved the final manuscript. 


\section{Funding}

The authors declare that they received no funding for their current research.

\section{Availability of data and materials}

The datasets used and/or analysed during the current study are available from the corresponding author on reasonable request.

\section{Declarations}

Ethics approval and consent to participate

The current study was approved by the local IRB, with written informed consents obtained from all participants.

\section{Consent for publication}

Not applicable.

\section{Competing interests}

The authors declare that they have no competing interests.

\section{Author details}

'Department of Neurosurgery, Mansoura University Hospital, Gomhurria Street, Mansoura, Egypt. ${ }^{2}$ Department of Vascular Surgery, Mansoura University Hospital, Mansoura, Egypt.

\section{Received: 12 March 2021 Accepted: 18 April 2021}

Published online: 01 November 2021

\section{References}

1. Alexander W. The treatment of epilepsy. J Ment Sci. 1889;35(150):239-40.

2. François-Frank M. Signification physiologique de la résection du sympathique dans la maladie de Basedow, l'épilepsie, l'idiotie et le glaucome. Bull Acad Med Paris. 1899;41:565-94.

3. Jaboulay M, Martin E. Chirurgie du grand sympathique et du corps thyroïde (les différents Goîtres). Lyon: A. Storck; 1900.

4. Jonnesco T. Resectia totala di bilaterala a simpaticului cervical in cazuri de epilepsie si gusa exoftalmica. Romania Med. 1896;4:479-81.

5. Jonnesco T. Angine de poitrine guérie par la résection du sympathique cervico-thoracique. Bull Acad Med. 1920;84:93-102.

6. De Takats G. Sympathectomy for hypertension. Am J Surg. 1974;127(5):521-4.

7. Hunter $\mathrm{Jl}$. The influence of the sympathetic nervous system in the genesis of the rigidity of striated muscles in spastic paralysis. Surg Gynecol Obstet. 1924;39:721-43.

8. Royle ND. A new operative procedure in the treatment of spastic paralysis and its experimental basis. Med J Aust. 1924;1:77-86.

9. Royle ND. The treatment of spastic paralysis by sympathetic ramisection. Proc R Soc Med. 1927;20(11):1799-804.

10. Harris JP, May J. Upper exterimity sympathectomy. In: Rutherford R, editor. Vascular surgery. 5th ed. Philadelphia:W B Saunders; 2000. p. 1222-32.

11. Hashmonai M, Schein M. Upper thoracic sympathectomy-open approaches. In: Paterson-Brown S, Garden J, editors. Surgical laparoscopy. London:W B Saunders; 1994. p. 587-603.

12. Haxton HA. Chemical sympathectomy. Br Med J. 1949;1:1026-8.

13. Alkosha HM, Elkiran YM. Predictors of long-term outcome of thoracic sympathectomy in patients with complex regional pain syndrome type-2. World Neurosurg. 2016;92:74-82.

14. Worsey J, Ferson PF, Keenan RJ, Julian TB, Landreneau RJ. Thoracoscopic pancreatic denervation for pain control in irresectable pancreatic cancer. $\mathrm{Br}$ J Surg. 1993;80(8):1051-2.

15. Telaranta T. Treatnent of social phobia by endoscopic thoracic sympathectomy. Eur J Surg Suppl. 1998;580:27-32. https://doi.org/10.1080/11024 159850191102

16. Le Jaboulay M. traitement de quelques troubles trophiques du pied et de la jambe par la dénudation de l'artère fémorale et la distension des nerfs vasculaires. Lyon Med. 1889;91:467-8.

17. De Leriche R. l'elongation et de la section des nerfs perivasculaires dans certains syndromes douloureux d'origine arterielle et dans quelques troubles trophiques. Lyon Chir. 1913;10:378-82.
18. Diez J. Un nuevo método de simpatectomía periférica para el tratamiento de las afecciones tróficas y gangrenosas de los miembros. Bol Soc Cir Buenos Aires. 1924;8:792-806.

19. Adson AW, Brown GE. The treatment of Raynaud's disease by resection of the upper thoracic and lumbar sympathetic ganglia and trunks. Surg Gynecol Obstet. 1929;48:577-603.

20. Goetz RH, Marr JAS. The importance of the second thoracic ganglion for the sympathetic supply of the upper extremities-two new approaches for its removal. Clin Proc. 1944;3:102-14.

21. Kao MC. Percutaneous radiofrequency upper thoracic sympathectomy. Neurosurgery. 1997;40:216-7.

22. Lin CC, Mo LR, Lee LS, Ng SM, Hwang MH. Thoracoscopic T2 sympathetic block by clipping - a better and reversible operation for treatment of hyperhidrosis palmaris: experience with 326 cases. Eur J Surg Suppl. 1998;580:13-6.

23. Adson AW, Brown GE. Raynaud's disease of the upper extremeties; successful treatment by resection of the sympathetic cervicothoracic and second thoracic ganglions and the intervening trunk. JAMA. 1929;92:444-9.

24. White JC, Smithwick RH, Allen AW, Mixter WJ. A new muscle splitting incision for resection of the upper thoracic sympathetic ganglia. Surg Gynecol Obstet. 1939;56:651-7

25. Telford ED. The technique of sympathectomy. Br J Surg. 1935;23:448-50.

26. Palumbo LT. Anterior transthoracic approach for upper thoracic sympathectomy. Arch Surg. 1956;72:659-66.

27. Atkins HJB. Sympathectomy by the axillary approach. Lancet. 1954;1:538-9.

28. Hughes J. Endothoracic sympathectomy. Proc R Soc Med. 1942;35:585-6.

29. Kux M. Thoracic endoscopic sympathectomy in palmar and axillary hyperhidrosis. Arch Surg. 1978;113:264-6.

30. Drott C, Gothberg G, Claes G. Endoscopic procedures of the upper thoracic sympathetic chain. A review. Arch Surg. 1993;128:237-41.

31. Solish N, Bertucci V, Dansereau A, et al. Canadian Hyperhidrosis Advisory Committee. A comprehensive approach to the recognition, diagnosis, and severity-based treatment of focal hyperhidrosis: recommendations of the Canadian Hyperhidrosis Advisory Committee. Dermatol Surg. 2007;33(8):908-23.

32. Vincent J. Collins principles of anaesthesiology. Blood volume determination. Philadelphia: Lea \& Febiger; 1976. p. 83.

33. De Campos JR, Kauffman P, Werebe Ede C, et al. Quality of life, before and after thoracic sympathectomy: report on 378 operated patients. Ann Thorac Surg. 2003;76(3):886-91.

34. Clavien P, Sanabria J, Strasberg S. Proposed classification of complication of surgery with examples of utility in cholecystectomy. Surgery. 1992;111:518-26.

35. Page ES. Continuous inspection schemes. Biometrika. 1954;41:100-15.

36. Rogers CA, Reeves BC, Caputo M, Ganesh JS, Bonser RS, Angelini GD. Control chart methods for monitoring cardiac surgical performance and their interpretation. J Thorac Cardiovasc Surg. 2004;128:811-9.

37. Gezer S, Avci A, Türktan M. Cusum analysis for learning curve of videothoracoscopic lobectomy. Open Med (Wars). 2016;11(1):574-7.

38. Grunkemeier GL, Wu XY, Furnary AP. Cumulative sum techniques for assessing surgical results. Ann Thorac Surg. 2003;76:663-7.

39. Lim TO, Soraya A, Ding LM, Morad Z. Assessing doctor's competence: application of CUSUM technique in monitoring doctor's performance. Int J Qual Health Care. 2002;14:251-8.

40. Waller HM, Connor SJ. Cumulative sum (Cusum) analysis provides an objective measure of competency during training in endoscopic retrograde cholangio-pancreatography (ERCP). HPB (Oxford). 2009;11(7):565-9.

41. Purtuloglua T, Atima A, Deniza $S$, et al. Effect of radiofrequency ablation and comparison with surgical sympathectomy in palmar hyperhidrosis. Eur J Cardiothorac Surg. 2013;43(6):e151-4. https://doi.org/10.1093/ejcts/ezt024.

42. Mostafa MS, Elsherbeny M, Abdelbarr A, Abdelhay S. Thoracoscopic excision versus radiofrequency ablation of the sympathetic chain as a treatment for palmar hyperhidrosis: comparative study. Ann Pediatr Surg. 2020;16(21):1-5. https://doi.org/10.1186/s43159-020-00031-1.

\section{Publisher's Note}

Springer Nature remains neutral with regard to jurisdictional claims in published maps and institutional affiliations. 